BLS 33, No 1 2007. DOI: http://dx.doi.org/10.3765/bls.v33i1.3537

(published by the Berkeley Linguistics Society and the Linguistic Society of America)

\title{
Debunking the Trochaic Bias Myth: Evidence from Phonological Development
}

\author{
YVAN ROSE \& CHRISTINE CHAMPDOIZEAU \\ Memorial University of Newfoundland
}

\section{Introduction}

Since the advent of the theory of Generative Grammar (e.g. Chomsky 1957), a large number of researchers have been on a quest to uncover language universals, which are believed by many to be psychologically real, either because they represent basic language storage or processing mechanisms, or because they emerge as artifacts of our perception or production systems. In many different ways, this quest has offered positive, useful results. Typological studies have yielded generalizations that suggest the presence of basic structures or mechanisms underlying the functioning of human languages. Similar generalizations were obtained from studies of language acquisition.

However, an undesirable effect of this quest has been, at times, somewhat hasty speculations that purported language universals should manifest themselves in language acquisition. Indeed, it is often the case that claimed universals end up representing cross-linguistic tendencies which themselves do not make any useful predictions in language acquisition. For example, while coronal consonants enjoy a special status in the phonological systems of a large number of the world's languages (e.g. Paradis \& Prunet 1991; Hall 1997), they display various behaviors in first language acquisition data that contradict the view that they should be universally unmarked or special in any way (e.g. Rose 2000).

In this paper, we argue that one such purported universal, often referred to as the trochaic bias, should be abandoned from the theory on a number of grounds. First, the cross-linguistic facts supporting this construct are far from conclusive. Second, babbling and early acquisition data do not provide any independent evidence for such a bias in phonological development. Finally, even in contexts where everything is in place to favor the manifestation of a bias towards trochaic footing, no convincing evidence can be found.

The paper is organized as follows. In section 1, we provide an overview of the predictions entailed by the trochaic bias as well as a brief survey of the literature on the topic in the context of child language phonology. As we will see, an overwhelming majority of the empirical evidence available fails to independently 
Yvan Rose and Christine Champdoizeau

support the trochaic bias as a valid construct. In Section 2, we discuss an apparent counter-example to this general observation. We however discredit this counterexample based on methodological considerations. We introduce the current study in section 3. As we will see, the data from this study also fail to provide support for the trochaic bias. We offer a brief summary and discussion in section 4 .

\section{The Trochaic Bias Hypothesis}

The trochaic bias hypothesis, as its name indicates, implies that trochaic, i.e. strong-weak (SW), foot form should be favored over other types of feet by Universal Grammar. To our knowledge, this hypothesis has been first proposed by Allen \& Hawkins (1978, 1980). As observed by these scholars, Englishlearning children tend to first preserve stressed and final syllables in the truncated forms they produce. For example, when producing WSW words such as banána or tomáto, these children showed a strong tendency to delete the first syllable altogether thereby producing a SW, trochaic word form. These results were later supported in works such as Demuth (1995), who provides a bottom-up account of the development of prosodic words based on data from English-learning children. However, Demuth does not claim that at the stage when feet are developing in children's prosodic representations, there is a bias for trochaic footing, despite the general trends uncovered by Allen and Hawkins' work.

Other scholars, however, have provided direct or indirect support to the trochaic bias hypothesis. For example, Fikkert (1994), in her study of the development of prosodic structure in first language Dutch learners, adopts a principleand-parameter approach according to which the learner's task is to set parameter values based on the evidence available from the input. Fikkert makes two key observations. First, similar to the English patterns described above, Dutch children tend to reduce long word forms to SW forms during early stages of phonological development. Second, these learners also show a tendency to pronounce target WS forms such as ballón 'balloon' as SW (Fikkert 1994: 203). Fikkert suggests that these observations can be related to a trochaic bias effect. (See also Kehoe 1997, 1998 for additional discussions of Fikkert's proposal based on acquisition data from English learners.)

\subsection{The Circularity Problem}

While the research reported above appears to lend support to the trochaic bias hypothesis, we argue here that none of the evidence put forth should be considered conclusive. Indeed, all of the supporting evidence comes from the acquisition of Dutch and English, two target languages that are uncontroversially analyzed as trochaic (e.g. Booij 1995, Hammond 1999). The patterns observed in the acquisition of these languages may in fact be triggered by the rhythmic properties of these languages, that is, the positive evidence that the learners of these languages are exposed to on a daily basis. The exposure to trochaic input is indeed likely to yield trochaic patterns without the need of any built-in bias towards a trochaic analysis of the language. 


\section{Debunking the Trochaic Bias Myth}

\subsection{Contradictory Evidence}

A further look at the literature on phonological development reveals a series of observations that contradict the existence of a trochaic bias even at the earliest stages of development, irrespective of the metrical properties of the target language.

\subsubsection{Evidence from Trochaic Languages}

Focusing first on English, Pollock, Brammer \& Hageman (1993) investigate the acoustic properties of stressed syllables produced by young learners of this language. Their study yields two important conclusions. First, they demonstrate that these learners have no generalized preference for trochaic stress patterns. Second, they show that at the production level, learners master the three acoustic parameters of stress (fundamental frequency, intensity and duration) independently. This second finding is important given that stress is realized through a combination of these parameters, whose realization is itself dependent on the system of segmental contrasts that exists in the language. For example, the relative duration of a stressed vowel is itself contingent on whether this vowel is phonologically tense (long) or lax (short). In addition, contextual effects must be considered, for example, the seemingly universal property of utterance-final syllables to display longer duration (e.g. Hayes 1995). The importance of considering all acoustic parameters of stress will be discussed further below.

Keeping with the trochaic bias hypothesis, one could hypothesize that trochaic bias effects are rather subtle and short-lived, and are rapidly hindered through language acquisition. In this context, it is necessary to look at the earliest linguistic productions, those found during the babbling stage. However, the evidence from such studies also generally contradicts the trochaic bias hypothesis. For example, Klein (1984) shows that both trochaic and iambic patterns are attested in babbles produced by an English-learning child. She concludes that stress is acquired lexically by children, at least during the initial stages of phonological development. Furthermore, Vihman, DePaolis \& Davis (1998) demonstrate from perceptual and acoustic evidence that children in fact appear to have their own rhythmic preferences in babbling, thereby contradicting predictions made by the trochaic bias hypothesis. The evidence they discuss from English-learning toddlers shows a nearly bipolar distribution between trochaic and iambic patterns in disyllabic babbles (only 56\% of the disyllabic babbles displayed a trochaic pattern), even though both a purported trochaic bias and the general rhythmic properties of English should in theory conspire to yield trochaic patterns in babbling. As Vihman et al. argue, the emergence of iambic patterns in their data may originate from words or phrases that constitute evidence for iambic footing, for example determiner + monosyllabic noun combinations, disyllabic phrases with final stress (e.g. $a$ báll). From an analysis of the rhythmic properties of childdirected speech from two caregivers in the same corpus, Vihman et al. show that children learning English are indeed exposed to a significant portion of iambic stress patterns (in approximately half of the child-directed utterances). 
Yvan Rose and Christine Champdoizeau

The authors conclude that children's patterns are not influenced by any builtin metrical bias. Rather, babblers appear to have their own analysis of the ambient evidence. Given that any analysis of English foot form as trochaic must be based on lexical stress patterns incorporating complicated evidence such as syllable weight and extrametricality, it is likely that babblers do not yet attend to all of this evidence. In addition, they have in their lexicon phrases such as $a$ ball that are not yet segmented into two words and, as such, are suggestive of iambic footing.

This possibility is in fact compatible with the evidence found in early word productions previously discussed for Dutch and English. Older children are likely to attend to the more complete set of evidence required to analyze the metrical properties of the target language. Once they arrive at this analysis, they will tend to generalize it over all forms, including those that do not show strong-weak patterns such as giraffe. These words may undergo stress shift or other modifications yielding the more general, trochaic pattern expected.

Similar findings are documented for the acquisition of other trochaic languages. For example, Hochberg (1988), who focuses on the acquisition of Spanish, finds no preference for trochaic or iambic footing in either non-word imitation tasks or real-word spontaneous production tasks. Similarly, Tzakosta (2004) recently demonstrated that learners of Greek may truncate WSW forms to either WS (iambic) or SW (trochaic) forms in early word productions. In line with the conclusions reached above for English, it is possible that the superficial properties of these target languages have an influence on the child's analysis. For example, in both Spanish and Greek, stress may fall on the final, penultimate or antepenultimate syllables, depending on a series of factors such as extrametricality, morphological structure and lexical idiosyncrasies. Such factors are likely to influence the acquisition of the metrical properties of the adult language.

While the complications noted above could be considered to hinder the effects of a potential bias, the existence of such a bias should however yield some preference for trochaic footing, which is evidently not the case. The only safe conclusion one can reach from these observations is that there is simply no such bias influencing children's early phonologies.

\subsubsection{Evidence from Iambic Languages}

Given that no evidence for the trochaic bias can be found in acquisition data from trochaic languages, which should in principle conspire with the trochaic bias to yield trochaic patterns, it is reasonable to expect that no such influence will be found in non-trochaic languages, mainly because of the absence of such a possible conspiracy between a hypothetical built-in bias and the evidence coming from the ambient language that the learner is exposed to. A survey of the literature on the acquisition of iambic languages fully supports this expectation. No trochaic bias appears to be found in the stress patterns, syllable truncation patterns or the development of complex word forms in iambic languages. These observations hold in languages such as Turkish (e.g. Aksu-Koç \& Slobin 1985), Yucatec Mayan (e.g. Archibald 1996) and French (e.g. Paradis, Petitclerc \& Genesee 


\section{Debunking the Trochaic Bias Myth}

1997, Vihman et al. 1998, Archibald \& Carson 2000, Rose 2000), whether the evidence comes from naturalistic, spontaneous productions or from more experimental approaches. For example, coming back to the Vihman et al. (1998) study discussed above in the context of English, these scholars also found that French learners' productions were overwhelmingly iambic, as opposed to the bipolar results found in the English data. The authors attribute this difference to the fact that stress patterns in French are extremely regular: only phrase-final syllables are stressed in this language. ${ }^{1}$

First language acquisition data thus fail to provide evidence for any kind of bias in the early production of stress by first language learners. We discuss an apparent counter-example to this generalization in the next section.

\section{Contradictory Results}

One apparent counter-example to the conclusions reached above for both trochaic and iambic languages comes from LaBelle's (2000) study of a bilingual, EnglishFrench first language learner. LaBelle argues from acoustic and perceptualimpressionistic assessments that this learner is in fact influenced by the trochaic bias, as she displays predominant trochaic patterns in both her English and French productions. In the lines that follow, we argue that LaBelle's conclusions are by and large unsupported, mostly due to methodological issues that prevent a clear assessment of this child's production patterns.

\subsection{LaBelle's (2000) study}

To determine which stress pattern was characterizing this bilingual child's speech, LaBelle primarily analyzed $\mathrm{F} \emptyset$ contours in one-word disyllabic utterances. $\mathrm{He}$ considered rising $\mathrm{F} \emptyset$ contours to be indicative of iambic stress and, conversely, associated falling $F \varnothing$ contours to trochaic stress. LaBelle included only declarative utterances in the analysis, since interrogative and imperative utterances typically have a rising intonational contours which could be suggestive of iambic stress.

Using the measurements obtained from the declarative utterances, an "impressionistic judgment was made regarding each token's stress pattern" (LaBelle, 2000: 476). The stress pattern was classified as having either iambic stress, trochaic stress or level stress, if the child equally stressed both syllables (not showing evidence of either stress pattern). The results from LaBelle's study indicate that the participant used mostly trochaic stress patterns (in 57\% of 33 French productions and $71 \%$ of 58 English productions). The tendencies observed in the data are suggestive of a predominantly trochaic influence, even in French utterances. LaBelle interprets this evidence as a manifestation of the trochaic bias.

\footnotetext{
${ }^{1}$ We come back to the properties of stress in French below in section 3.1.
} 
Yvan Rose and Christine Champdoizeau

\subsection{Criticism}

While LaBelle's (2000) conclusions seemingly support the trochaic bias hypothesis, we argue that these conclusions may in fact be an artifact of the method he used to analyze the child's productions. As mentioned above, the evidence that LaBelle uses comes primarily from an analysis of $F \varnothing$ curves. However, we argue that such an approach is flawed, because it makes it impossible to determine with certainly what syllable was in fact stressed by the child. Indeed, as noted previously, stress can be realized across languages through the enhancing of one of three acoustic parameters ( $\mathrm{F} \varnothing$, intensity and duration) or of any combination of these parameters. Although LaBelle mentions measurements of all three parameters, he did not incorporate intensity and duration in his assessment of the child's productions. This approach is especially problematic since English and French utilize very different cue combinations to realize stress. As we will see below, while $F \emptyset$ is important to English stress, it is virtually irrelevant to French stress. In this context, it appears that LaBelle was not considering all of the required evidence to test his hypothesis.

An additional argument arises from this criticism. Given that utterance-final intonation is typically falling in both English and French declarative sentences, and that a falling $F \varnothing$ curve on the final syllable is interpreted by LaBelle as evidence for trochaic footing, it is no surprise that the evidence he found based on FØ measurements was supportive of the trochaic bias.

Building on this discussion, we introduce our current study in the next section.

\section{Current study}

Our study is based on one learner, code-named Anne, who was raised in a bilingual, English-French household in St. John's, Canada. St. John's is the capital city of the province of Newfoundland and Labrador where English is clearly the predominant language. The French-speaking population of St. John's is indeed restricted to a few hundred individuals, virtually all of whom also speak English as a second language. We recorded Anne's linguistic development for a period of approximately two years (from 2;00.04 to 4;02.25). Our study focuses more specifically on the first year of recordings. At the time of the study, Anne could understand virtually everything that was spoken to her in French. However, she was overwhelmingly English-dominant. We believe that this dominance arose from her then recent entry into a monolingual English daycare center, where she was in regular contact with a monolingual community of English-speaking peers. Consistent with her preference for English, Anne avoided French as much as possible, even with French interlocutors. As a result, most of her French productions arose from code-switches. We recorded Anne on a fortnightly basis following a one-speaker, one-language protocol, i.e. alternating English and French interlocutors across recording sessions. 


\section{Debunking the Trochaic Bias Myth}

\subsection{Method}

In line with LaBelle, we analyzed declarative utterances only. We performed acoustic analyses of Anne's stress patterns in both French $(n=36)$ and English $(n=38)$ disyllabic words. However, we excluded from our analysis English words with final stress such as ballóon, since comparisons between penultimate and final syllables in such words would wrongly suggest iambic patterning. In addition, we measured and considered all three cues that are potentially relevant for stress assignment: $F \emptyset$ and intensity peaks as well as vowel duration. We measured both the final and the penultimate vowels of each utterance-final word and then compared the measurements obtained across syllable positions. For each parameter, larger values on the penultimate syllable indicated trochaic stress while larger values on the final syllable were interpreted as evidence for iambic stress.

As alluded to above, a consideration of all three acoustic cues is paramount in such a study, since the acoustic manifestations of stress in English and French involve significantly different cue combinations. In English, stressed syllables involve higher FØ and intensity values (Fry 1955, Lieberman 1960, Beckman 1986), in addition to increased duration, modulo the tense/lax contrast between vowels, which is in part manifested through vowel length. As opposed to English, stressed syllables in French are primarily characterized by increased vowel duration (Delattre 1966, Léon 1996, Vaissière 1997). Intensity and FØ in French are mostly related to intonation and sentential focus.

\subsection{The Relevance of this Study}

As can be inferred from our methodology, virtually everything needed to encourage the emergence of trochaic bias effects was in place. First, our participant, despite living in a bilingual household, was raised in the overwhelmingly Englishspeaking environment of St. John's. Moreover, at the time of the study, she was attending a monolingual, English-speaking daycare center, to which we attribute her generalized preference for English and obvious avoidance of French productions. In this context, while the emergence of a trochaic bias in her productions could be attributed to her linguistic environment, the absence of such an emergent property in her speech should provide significant empirical evidence against the existence of a trochaic bias.

\subsection{Results}

We analyzed the results from two different perspectives. First, we analyzed the overall differences observed by the penultimate and final syllables for each acoustic parameter. As can be seen in (1), a falling curve between the penultimate and final syllables is found for each acoustic parameter in English productions. These results generally correspond to what should be expected in this language. As opposed to this, we find mixed and relatively flat results for $F \emptyset$ (slightly falling) and intensity (slightly rising) in French, with a clearly rising curve for duration. Again here, the results closely match the parameters of the target 


\section{Yvan Rose and Christine Champdoizeau}

language, in which, as already mentioned, stress is mainly realized through increased vowel duration.

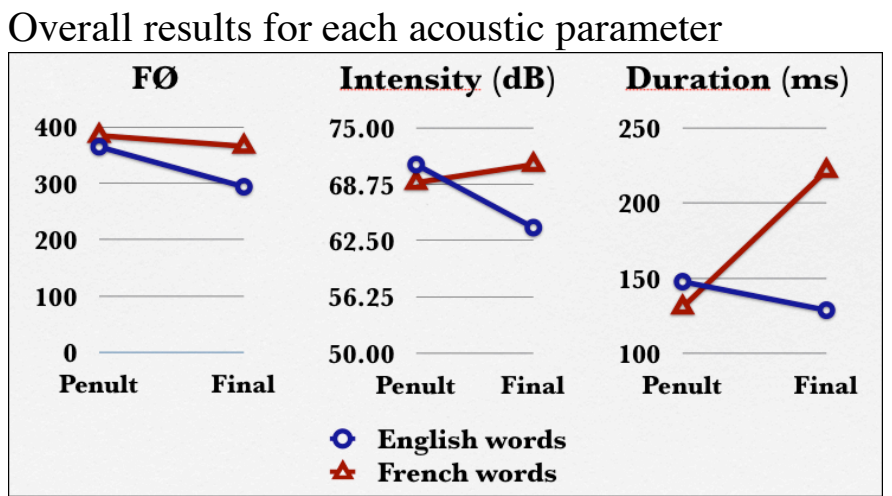

The general tendencies depicted in (1), which are already suggestive of a separation between the two languages in the child's productions, and of a relatively native-like behavior in each language, do not however provide indication on stress patterns produced in individual words. The next two figures provide an analysis of trochaic versus iambic patterns for both English and French. As can be seen in (2), the child's English productions generally followed a trochaic pattern if one considers $F \varnothing$ and intensity, the two clearest acoustic parameters of stress in this language.

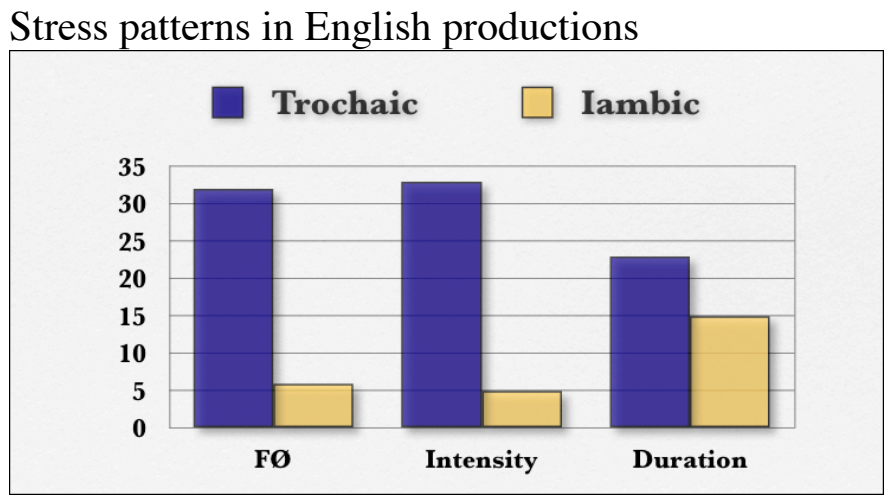

However, the results from duration are more mixed. We attribute these results to a combination of potential factors. As already mentioned, vowel duration in English is relevant not only to stress but also to the phonological contrast that exists between tense and lax vowels. In addition, vowel duration in English is also influenced by factors such as the voicing of post-vocalic consonants (e.g. Borden et al. 2003). Finally, other general influences such as the lengthening of utterance- 


\section{Debunking the Trochaic Bias Myth}

final vowels may further influence these results. ${ }^{2}$ Despite all of these complications, we do observe a majority of trochaic patterns based on duration.

A comparison of the stress patterns in English words in (2) with those in French words in (3) reveals clear qualitative and quantitative differences. First, we see the overall stress pattern shifting to an iambic one. In addition, instead of displaying clear patterns for $\mathrm{F} \varnothing$ and intensity as we saw in (2), the only dominant stress pattern found in French words relates to duration. These data clearly demonstrate that when uttering French words, the child correctly produced an iambic stress pattern, using the only acoustic correlate relevant to French stress, that is, increased duration of the final syllable.

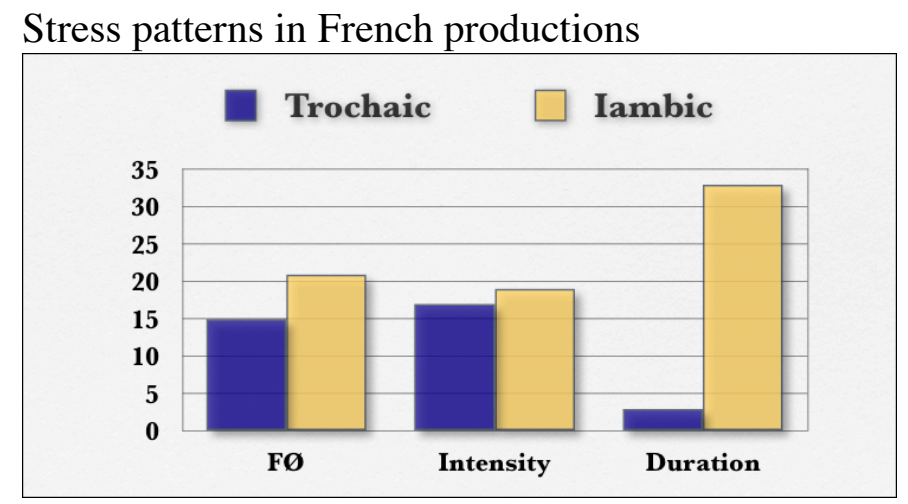

As noted above, there appears to be a universal tendency for vowel lengthening in utterance-final syllables across languages (Hayes 1995). It is possible that this tendency for final lengthening, which presumably has articulatory or aerodynamic sources, conspires with the acoustic properties of French to yield such a clear result. However, this possibility should not detract us from the observation that the child's productions are nonetheless largely compatible with the metrical and acoustic properties of French stress. In this context, it is important to note the marginal patterns found with the other two acoustic parameters, especially in light of the fact that these two parameters are the ones that are mostly exploited to phonetically realize stress in the English data.

\subsection{Interpretation}

The results emerging from the measurements of the English and French productions provide us with compelling indications about both the child's metrical analysis and overall mastery of the acoustic correlates of stress that are relevant to each language. These two observations are evident from the schema in (4), which combines the results from both languages. As we can see in this comparative summary, the child not only generally displayed the correct stress patterns in each

\footnotetext{
${ }^{2}$ Full testing of such influences would require analysis of variance based on a larger number of examples for each relevant context. This issue, which extends beyond the scope of this case study, is left for future investigation.
} 
language, she also demonstrated great control of the acoustic correlates of stress in each of the two languages.

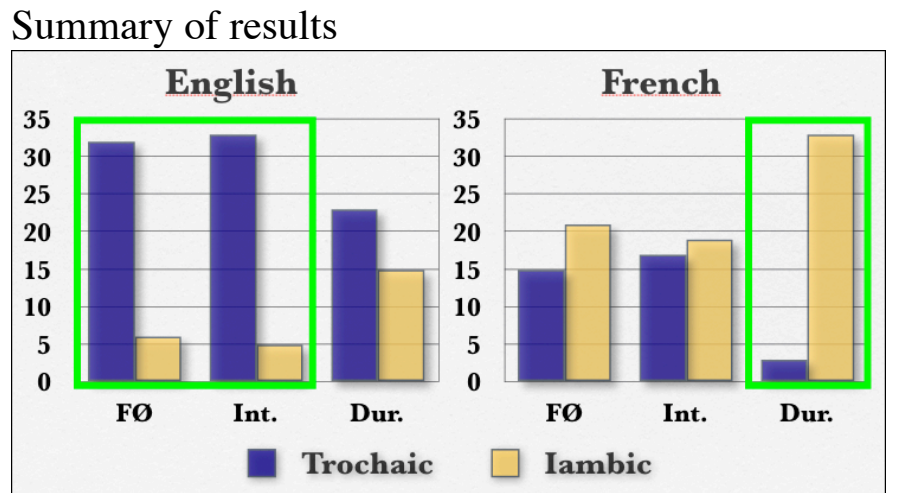

Indeed, English productions are mostly realized through an increase of $F \emptyset$ and intensity on the penultimate syllable, with a more marginal role left to increased duration, while the only clear pattern that arises from the French productions relates to an increased duration of the final syllable. In sum, the child's productions are generally native-like in both of her languages.

The results from our study contradict the trochaic bias hypothesis. Indeed, while the child displayed trochaic stress patterns in her English production, no such patterns were found in the French data. These results are particularly significant in light of the general context of the study, which is based on a clearly English-dominant learner who was raised in an English-dominant environment. These results also contradict those of LaBelle's (2000) study. Even though we are not in a position to verify the source of the differences between the two studies, we attribute it to the different methods used in each. Furthermore, based on our criticism of LaBelle's study, we speculate that a detailed investigation of the acoustic parameters relevant to each of the languages may have yielded different conclusions.

\section{Discussion}

In this paper, we discussed the controversial status of the trochaic bias, a theoretical construct suggesting an inborn bias towards trochaic footing in child language. We first provided a survey of the background literature on the topic. Based on this survey we concluded that there is currently no independent evidence supporting the presence of this bias in child language. While all of the evidence available in support of such a bias is confined to the acquisition of trochaic languages, thereby posing a circularity problem, a significant body of evidence, coming from the acquisition of both trochaic and iambic languages, contradicts the trochaic bias hypothesis. We then discussed findings by LaBelle (2000) that apparently contradict this conclusion. We rejected these results as inconclusive on methodological grounds. We then introduced our study, which consists of a metrical and acoustic 


\section{Debunking the Trochaic Bias Myth}

analysis of words produced by a bilingual learner. This learner provides a good test case for our hypothesis against a trochaic bias in child language because of her language dominance and her general linguistic environment, both of which would likely favor the manifestation of such a bias in her word productions. Based on acoustic measurements of the fundamental frequency, intensity and duration of the penultimate and final vowels produced by this child in both English and French words, we demonstrated that the child had mastered both the basic metrical properties and the most central acoustic correlates of stress of each of the target languages.

The results of our investigation clearly contradict the presence of a trochaic bias in the child's phonology. Similar to the findings from the literature on babbling and first word productions reported above, the current results fail to provide empirical support for the trochaic bias. In fact, these results overwhelmingly suggest that the only biases that the learners are subject to come from the phonological and acoustic properties of the target languages. Based on the absence of any clear, independent empirical support for the trochaic bias, we thus propose that this construct is nothing more than a myth and, as such, should be eliminated from any theoretical claims about the cognitive foundations of stress systems in human languages.

\section{References}

Aksu-Koç, Ayhan and Dan Slobin. 1985. The Acquisition of Turkish. In The Crosslinguistic Study of Language Acquisition, Volume 1: The Data, edited by Dan Slobin. Hillsdale, NJ: Lawrence Erlbaum Associates.

Allen, George and Sarah Hawkins. 1978. The Development of Phonological Rhythm. In Syllables and Segments, edited by Alan Bell and Joan Bybee Hooper. Amsterdam: North Holland. . 1980. Phonological Rhythm: Definition and Development. Child Phonology 1:227256.

Archibald, John. 1996. The Acquisition of Yucatecan Maya Prosody. In Proceedings of the UBC International Conference on Phonological Acquisition, edited by Barbara Bernhardt, John Gilbert and David Ingram. Somerville, MA: Cascadilla Press.

Archibald, John and Jana Carson. 2000. Acquisition of Quebec French Stress. In Proceedings of the 2000 Annual Meeting of the Canadian Linguistics Association, edited by John Jensen and Gerard van Herk. Ottawa: University of Ottawa.

Beckman, Mary. 1986. Stress and Non-Stress Accent. Dordrecht: Foris.

Booij, Geert. 1995. The Phonology of Dutch. Oxford: Oxford Clarendon Press.

Borden, Gloria, Katherine Harris and Lawrence Raphael. 2003. Speech Science Primer, 4th Edition. Philadelphia: Lippincott Williams \& Wilkins.

Chomsky, Noam. 1957. Syntactic Structures. The Hague: Mouton.

Delattre, Pierre. 1966. A Comparison of Syllable Length Conditioning Among Languages. International Journal of Applied Linguistics 4:182-198. 
Yvan Rose and Christine Champdoizeau

Demuth, Katherine. 1995. Markedness and the Development of Prosodic Structure. In Proceedings of the North East Linguistic Society (NELS), edited by Jill Beckman. Amherst: Graduate Linguistic Student Association.

Fikkert, Paula. 1994. On the Acquisition of Prosodic Structure. Dordrecht: ICG Printing. Fry, Dennis. 1955. Duration and Intensity as Physical Correlates of Linguistic Stress. Journal of the Acoustical Society of America 27:765-768.

Hall, Tracy Alan. 1997. The Phonology of Coronals. Philadelphia: John Benjamins. Hammond, Michael. 1999. The Phonology of English. Oxford: Oxford University Press. Hayes, Bruce. 1995. Metrical Stress Theory: Principles and Case Studies. Chicago: The University of Chicago Press.

Hochberg, Judith. 1988. Learning Spanish Stress: Developmental and Theoretical Perspectives. Language 64:683-706.

Kehoe, Margaret. 1997. Stress Error Patterns in English-speaking Children's Word Productions. Clinical Linguistics and Phonetics 11:389-409. . 1998. Support for Metrical Stress Theory in Stress Acquisition. Clinical Linguistics and Phonetics 12:1-23.

Klein, Harriet. 1984. Learning to Stress: A Case Study. Journal of Child Language 11:375-390.

LaBelle, Christopher. 2000. A Longitudinal Study of Lexical and Prosodic Differentiation by a Simultaneous French/English Bilingual Child. In Proceedings of the 24th Annual Boston University Conference on Language Development, edited by Catherine Howell, Sarah Fish and Thea Keith-Lucas. Somerville, MA: Cascadilla Press.

Léon, Pierre. 1996. Phonetic Changes and Variations in Contemporary French: Linguistic and Semiotic Factors. Revue de Phonétique Appliquée 120:201-219.

Lieberman, Philip. 1960. Some Acoustic Correlates of Word Stress in American English. Journal of the Acoustical Society of America 32:451-454.

Paradis, Carole and Jean-François Prunet, eds. 1991. The Special Status of Coronals: Internal and External Evidence. Vol. 2, Phonetics and Phonology Series. San Diego: Academic Press.

Paradis, Johanne, Sophie Petitclerc and Fred Genesee. 1997. Word Truncation in Frenchspeaking Two-year-olds. In Proceedings of the 21 st Annual Boston University Conference on Language Development, edited by Elizabeth Hughes, Mary Hughes and Annabel Greenhill. Somerville, MA: Cascadilla Press.

Pollock, Karen, Dianne Brammer and Carlin Hageman. 1993. An Acoustic Analysis of Young Children's Productions of Word Stress. Journal of Phonetics 21:183-203.

Rose, Yvan. 2000. Headedness and Prosodic Licensing in the L1 Acquisition of Phonology. Ph.D. Dissertation, McGill University.

Tzakosta, Marina. 2004. Multiple Parallel Grammars in the Acquisition of Stress in Greek L1. Utrecht: LOT.

Vaissière, Jacqueline. 1997. Langues, prosodie et syntaxe. Revue Traitement Automatique des Langues 38:53-82.

Vihman, Marilyn, Rory DePaolis and Barbara Davis. 1998. Is there a "Trochaic Bias" in Early Word Learning? Evidence from Infant Production in English and French. Child Development 69:935-949. 